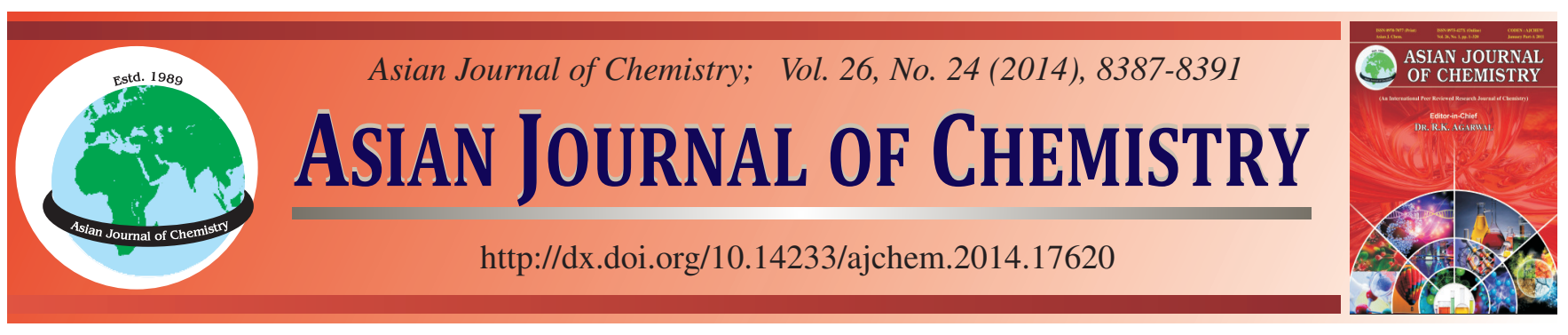

\title{
Anion Exchange Solid-Phase Extraction Combined with High Performance Liquid Chromatography to Determine Bensulfuron Methyl in Wheat and Soil
}

\author{
M. Wu and J.Y. Hu ${ }^{*}$
}

School of Chemistry and Biological Engineering, University of Science and Technology Beijing, Beijing 100083, P.R. China

*Corresponding author: Tel/Fax: +86 10 82376002; E-mail: jyhu@ustb.edu.cn

\begin{abstract}
A simple and reliable method based on solid-phase extraction with anion exchange column was developed for the determination of bensulfuron methyl residues in soil, wheat straw and grain by high performance liquid chromatography with an ultraviolet detector (HPLC-UV). The average recoveries were found ranged from 83.3 to $99.5 \%$ with RSD values less than $6.85 \%$, at fortification levels of $0.01 / 0.05,0.1$ and 0.5 $\mathrm{mg} / \mathrm{kg}$. The validated method has been successfully applied to analyze the dissipation and residues of bensulfuron methyl in Beijing, Shandong and Anhui Provinces, China. The half-lives of bensulfuron methyl in soil and wheat straw from experimental field were $4.62-8.66$ days and 2.39-4.05 days, respectively. The terminal residues of bensulfuron methyl in wheat grain were all below maximum residue level value set by China $(0.02 \mathrm{mg} / \mathrm{kg})$. The pesticide extracted from field sample was confirmed by liquid chromatography-mass spectrometry (LC-MS).
\end{abstract}

Keywords: Anion exchange column, Bensulfuron methyl, High performance liquid chromatography, Residue analysis.

\section{INTRODUCTION}

Bensulfuron methyl (Fig. 1) is a kind of ultra-efficient sulfonylurea herbicides with high activity and low toxicity ${ }^{1}$, which was introduced in 1982 by Dupont Agricultural Products and widely used for weed control in agronomic crops ${ }^{2}$, such as rice, rapeseed, barley, wheat and maize. This class of herbicides act through inhibition of acetolactate synthase (specific to plants and microorganisms), thereby blocking the biosynthesis of the branched-chain amino acids valine, leucine and isoleucine ${ }^{3}$. This inhibition leads to the rapid cessation of plant cell division and growth. As with other herbicides, bensulfuron methyl is characterized by broad-spectrum weed control at very low application rates, good crop selectivity and chronic animal toxicity and no propensity to bioaccumulate in nontarget organisms ${ }^{4}$. Its commonly use causes an increasing concern when studies showed a potential environmental hazard $^{5-10}$.

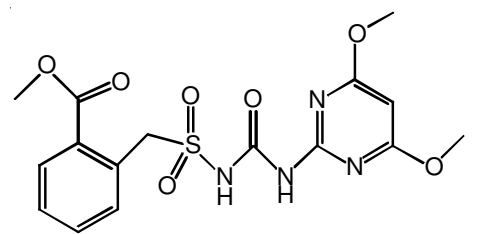

Fig.1 Chemical structure of bensulfuron methyl

Several methods have been proposed for the determination of bensulfuron methyl, mainly involving the use of HPLC ${ }^{11-14}$,
HPLC-MS ${ }^{15-17}$ and immunoassay ${ }^{18-19}$. Previous study evaluated adsorbents (hydrophobic interaction or polar adsorption) for the purification of sulfonylurea herbicides, such as C18, PSA, graphite carbon black and Oasis HLB ${ }^{20-22}$. Taking into account that the $\mathrm{pKa}$ values for sulfonylurea herbicides ranged from 3.6 to $6.0^{23}$, they were $\mathrm{pH}$ dependent weak acid herbicides. In terms of this character, anion exchange column (selective ionexchange) is the best suited for high purification efficiency, combined with HPLC to obtain a sensitive and inexpensive analytical method. However, to our best of knowledge, there is no research on this kind of pesticide purified with anion exchange solid-phase extraction column.

In this paper, a simple and selective HPLC-UV analytical method with a powerful cleanup procedure based on anion exchange column (PAX/SAX) was established to analyze bensulfuron methyl in wheat and soil samples. The residue and dissipation dynamics behaviour of bensulfuron methyl in wheat and soil were also studied. The data from this paper will help provide guidance on the proper and safe use of bensulfuron methyl. Moreover, it will also provide scientific advice for the use of anion exchange column.

\section{EXPERIMENTAL}

Bensulfuron methyl standard (99\% purity) and its preparation $(60 \%$, WDG) were provided by Jiangsu Ruihe Chemical Co., Ltd. (Jiangsu, China). HPLC grade methanol and acetonitrile and other analytical grade reagents and chemicals were 
procured from Dikma Ltd. All pH measurements were made with a pHs-3C digital pH-meter (Shanghai Lei Ci Device Works, Shanghai, China) with a combined glass calomel electrode. solid-phase extraction columns (PAX, $60 \mathrm{mg} / 3 \mathrm{~mL}$; $\mathrm{SAX}, 500 \mathrm{mg} / 3 \mathrm{~mL}$ ) were purchased from Agela Technologies (Tianjin, China).

Standard solutions: A stock solution of bensulfuron methyl $(502 \mu \mathrm{g} / \mathrm{mL})$ was prepared in methanol containing $0.5 \%$ ammonia and stored at $-20^{\circ} \mathrm{C}$. Standard solutions $(0.01$, $0.05,0.1,0.5,1.0$ and $5.0 \mu \mathrm{g} / \mathrm{mL}$ ) were prepared from the stock solution by serial dilutions. All solutions were stored in brown volumetric flask in a refrigerator at $4{ }^{\circ} \mathrm{C}$.

Instrumental analysis: An HPLC system (Shimadzu, Kyoto, Japan) equipped with an analytical column (250 mm $\times 4.6$ I.D., $5 \mu \mathrm{m} \mathrm{C18)} \mathrm{was} \mathrm{attached} \mathrm{to} \mathrm{a} \mathrm{UV} \mathrm{detector.} \mathrm{A} \mathrm{total}$ flow rate was $1 \mathrm{~mL} / \mathrm{min}$ and the injection volume was $20 \mu \mathrm{L}$ for all samples. Detection was performed at $245 \mathrm{~nm}$. All measurements were carried out at room temperature. The chromatographic conditions used for the analysis of bensulfuron methyl residues were as follows: the mobile phase in soil sample was methanol and water containing $0.03 \%$ phosphoric acid (68:32, $\mathrm{v} / \mathrm{v})$, the retention time was about $12 \mathrm{~min}$; the mobile phase in wheat straw sample was methanol and acetonitrile and water containing $0.03 \%$ phosphoric acid (27.5:27.5:45, v/v/v), the retention time was about $23 \mathrm{~min}$; the mobile phase in wheat grain sample was methanol and water containing $0.03 \%$ phosphoric acid (60:40, v/v), the retention time was about $23 \mathrm{~min}$.

Direct confirmation of the analyte in the sample was realized by Shimadzu LCMS-8040 under the following conditions: flow rate $0.5 \mathrm{~mL} / \mathrm{min}$, temperature $40{ }^{\circ} \mathrm{C}$, the mobile phase was methanol and water containing $0.1 \%$ formic acid $(60: 40, \mathrm{v} / \mathrm{v})$ and the injection volume was $0.1 \mu \mathrm{L}$. Mass Detector parameters: nebulizing gas flow $3 \mathrm{~L} / \mathrm{min}$; drying gas flow $15 \mathrm{~L} / \mathrm{min}$; block heater $450{ }^{\circ} \mathrm{C}$; the retention time of bensulfuron methyl was about $1.9 \mathrm{~min}$. detector voltage $1.84 \mathrm{kV}$; collision energy (-25 V, $m / z$ 149.1; -22 V, $m / z, 182.1)$.

Sample preparation: Ten grams of sample was extracted with $60 \mathrm{~mL}$ methanol-water $(1: 1, \mathrm{v} / \mathrm{v})$ in a $250 \mathrm{~mL}$ conical flask and shaken for $60 \mathrm{~min}$ at room temperature. The extract was filtered through a $12 \mathrm{~cm}$ Buchner funnel and transferred to a separating funnel, after which $30 \mathrm{~mL} 2 \%$ aqueous sodium sulfate solution was added, followed by adding $3 \mathrm{~mol} / \mathrm{L} \mathrm{HCl}$ to obtain a $\mathrm{pH}$ of approximately 3 . The filtrate was partitioned with dichloromethane three times sequentially $(3 \times 20 \mathrm{~mL})$. The combined dichloro-methane extract was dehydrated with anhydrous sodium sulfate, evaporated to near dryness with a vacuum rotary evaporator at $40^{\circ} \mathrm{C}$ and completely dried under a gentle nitrogen stream. Solid-phase extraction procedures are as follows:

For soil sample, the residues were dissolved in $3 \mathrm{~mL}$ water (pH 11), of which $2 \mathrm{~mL}$ sample solution was loaded on PAX cartridge preconditioned with $2 \mathrm{~mL}$ of methanol and $2 \mathrm{~mL}$ of water $(\mathrm{pH} 11)$. The cartridge was washed with $2 \mathrm{~mL}$ water (pH 11), 2 mL methanol and the eluate was discarded. Analyte was eluted with $1 \mathrm{~mL}$ methanol-5 mol/L $\mathrm{HCl}(100: 1, \mathrm{v} / \mathrm{v})$ and concentrated to dryness. Finally, the resulting residue was redissolved in $2 \mathrm{~mL}$ methanol for HPLC analysis.

For wheat straw sample, the residues were dissolved in $5 \mathrm{~mL}$ water ( $\mathrm{pH} 11)$, of which $2 \mathrm{~mL}$ sample solution was loaded on SAX cartridge preconditioned with $2 \mathrm{~mL}$ of methanol, 2 $\mathrm{mL}$ of water $(\mathrm{pH} 11)$. The cartridge was successively washed with $2 \mathrm{~mL}$ water $(\mathrm{pH} 11)$-methanol (98:2, v/v), $1 \mathrm{~mL}$ water (pH 11)-methanol (95:5, v/v), $1 \mathrm{~mL}$ water $(\mathrm{pH} 1.5)$ and the eluate was discarded. Analyte was eluted with $2 \mathrm{~mL}$ water $(\mathrm{pH} 1)$-methanol $(9: 1, \mathrm{v} / \mathrm{v})$ and the eluate was collected for HPLC analysis.

For wheat grain sample, the residues were dissolved in $3 \mathrm{~mL}$ water ( $\mathrm{pH} 11$ ), of which $2 \mathrm{~mL}$ sample solution was loaded on SAX cartridge preconditioned with $2 \mathrm{~mL}$ of methanol, $2 \mathrm{~mL}$ of water ( $\mathrm{pH} 11$ ). The cartridge was washed with $2 \mathrm{~mL}$ watermethanol $(98: 2, \mathrm{v} / \mathrm{v})$ and the eluate was discarded. Analyte was eluted with $2 \mathrm{~mL}$ water ( $\mathrm{pH}$ 1)-methanol $(85: 15, \mathrm{v} / \mathrm{v})$ and the eluate was collected for HPLC analysis.

Field trials: The trial was carried out in three experimental plots, located in Beijing, Shandong and Anhui from March to June 2012. The experiments were designed according to NY/ T 788-2004 (Guideline on Pesticide Residue Trials) issued by Ministry of Agriculture, People's Republic of China. Each experimental block was $30 \mathrm{~m}^{2}$ and each treatment replicated three plots. The control plots were localized, tagged and separated by guard rows to avoid contaminating by drift. In order to investigate the dissipation of bensulfuron methyl in soil and wheat straw, bensulfuron methyl (60\%, WDG) was sprayed at a dosage of $108 \mathrm{~g}$ a.i./ha (gram of active ingredient per hectare, 1.5 times of the recommended dose) in the experimental spots. To investigate the terminal residue of bensulfuron methyl in wheat field, $72 \mathrm{~g}$ a.i./ha (recommended dose) and $108 \mathrm{~g}$ a.i./ha were conducted during the jointing stage in two plots, separately. In control blocks, only water was sprayed.

Soil and wheat straw samples were collected at random from each plot at 0 ( $2 \mathrm{~h}$ after application), 1, 3, 5, 7, 14, 21, 30 days after the herbicide application. Soil samples were collected from different depths ranging from 0 to $10 \mathrm{~cm}$ with a soil sampler, then air-dried, mixed and sieved through a $2 \mathrm{~mm}$ mesh; wheat straw samples were chopped, thoroughly mixed and divided into three sub-samples each; wheat grain were collected at harvest time and immediately put into polyethylene bags and transported to the laboratory where they were airdried in room temperature and ground into powder. All of the sub-samples were kept in a deep frozen $\left(-20^{\circ} \mathrm{C}\right)$ environment until analysis.

\section{RESULTS AND DISCUSSION}

Optimization of sample purification: solid-phase extraction is a widely used sample-preparation technique for concentration and cleanup in the pesticide residue analysis field. In this paper, a type of anion exchange column packed with silica based sorbent bonded with a quaternary amine is introduced, which is used to extract compounds capable of carrying a negative charge from both aqueous and non-aqueous solutions. It is ideally suitable to extraction of weak acids like sulfonylureas. Separation of bensulfuron methyl is first achieved by adjusting the eluent $\mathrm{pH}$. Since bensulfuron methyl has a pKa of approximately 5.2, it would be in anionic form above the pKa and bound to the cation exchange resin and then different polar compounds would be eluted gradually with an increase in methanol concentration as well as decrease in $\mathrm{pH}$ value $\mathrm{e}^{24}$. It is necessary to use an acid (at least $2 \mathrm{pH}$ units lower than the 
$\mathrm{pKa}$ ) to elute the analyte, to ensure the analyte in the molecular form and thusly be more easily retained. Considering all above factors, good separation and quantification could be achieved.

Optimization of HPLC conditions: Taking into account that the $\mathrm{pKa}$ values for bensulfuron methyl, the $\mathrm{pH}$ value of the mobile phase was corrected with phosphoric acid to favour the predominance of the neutral acidic species and increase the retention. The best separation was obtained with an aqueous phase $0.03 \%$ in volume in phosphoric acid.

Standard curve: A standard curve of bensulfuron methyl was constructed by plotting the analyte concentration (x) against peak areas (y) under the proposed chromatographic conditions. A good linearity was achieved from 0.01 to $5.0 \mathrm{mg} / \mathrm{kg}$ with correlation coefficients $\left(\mathrm{R}^{2}\right)$ of 0.9999 . The standard curve equation was $\mathrm{y}=51630.11 \mathrm{x}-106.7831$.

Validation of the proposed analytical method: Recoveries of the pesticide are given in Table-1. Satisfactory results found in soil, wheat straw and grain sample for bensulfuron methyl were 80.6-103, 84.3-102 and 80.8-105\%, respectively. The uncertainty associated with the analytical method, expressed as relative standard deviation (RSD), were 2.05-6.85, 2.166.80 and $1.25-4.50 \%$ for the pesticide tested in corresponding matrices. Fig. 2 shows the typical chromatograms of the blank and spiked samples. No interference from the matrix was found in the analysis of blank soil, wheat straw and grain samples by HPLC-UV. The limit of detection (a signal-to-noise ratio of three) was estimated to be $0.003 \mathrm{mg} / \mathrm{kg}$. The limit of quantification (LOQ) is the lowest concentration of the analyte in a sample that can be determined with acceptable precision and accuracy under the stated experimental conditions. The LOQ was found to be $0.01,0.05$ and $0.01 \mathrm{mg} / \mathrm{kg}$ in soil, wheat straw and grain, respectively.

Persistence of bensulfuron methyl: Under field conditions, all residue data were subjected to statistical analysis to evaluate the dissipation of bensulfuron methyl. The dissipation of bensulfuron methyl in soil and wheat straw can be described mathematically by a pseudo-first rate equation. The values of the dissipation equation and regression coefficients are listed in Table-2. The half-lives of bensulfuron methyl were 4.628.66 days in soil in Beijing, Shandong and Anhui, while 2.394.05 days in wheat straw and $92-98 \%$ of the residue had dissipated after 14 days (Fig. 3). It clearly shows a relatively fast decline. Rates of dissipation are influenced by physicochemical properties of the soil ( $\mathrm{pH}$ and organic carbon content), biological properties (activity and distribution of microorganisms) and environmental conditions that control soil temperature and moisture content. In this study, different physical and chemical characteristics of three soils and rainfall fluctuated the dissipation of bensulfuron methyl.

From the data obtained in terminal residue test (Table-3), no bensulfuron methyl residues $(<0.01 \mathrm{mg} / \mathrm{kg})$ were detected in wheat grain at harvest time. Due to the use pattern, the maximum residue level (MRL) has been established as 0.02 $\mathrm{mg} / \mathrm{kg}$ for wheat in China ${ }^{25}$, which indicated that the application of bensulfuron methyl (60\%, WDG) at the recommended dose in wheat field is safe. In recent years wheat straw is greatly underutilized as a feedstuff and there were no MRLs of pesticides established for plant straw in China, so the terminal residue of bensulfuron methyl in wheat straw should receive more concern. Our study could provide reference for establishing the relevant MRL standard in China.

In Fig. 4, presence of bensulfuron methyl in field-treated soil samples was confirmed by LC-MS with a total ion chromatogram and expected MS spectrum with molecular ion peak at $m / z 411.0$ and the specific fragment ions at $m / z 149.1,182.1$, 213.0. Similar result was reported by Pareja et al. ${ }^{26}$ and the probable fragmentation pathways of protonated bensulfuron methyl are shown in Fig. 5.

\section{Conclusion}

A simple and reliable HPLC method based on anion exchange column for sample purification was developed and validated for determination of bensulfuron methyl residues in soil, wheat straw and wheat grain. The method shows satis-

\begin{tabular}{|c|c|c|c|c|c|c|}
\hline \multirow{3}{*}{ Matrix } & \multicolumn{5}{|c|}{$\begin{array}{l}\text { TABLE-1 } \\
\text { RECOVERIES OF BENSULFURON METHYL IN SOIL, WHEAT STRAW AND GRAIN }(n=3)\end{array}$} & \multirow{3}{*}{$\operatorname{RSD}(\%)$} \\
\hline & \multirow{2}{*}{ Spiked level (mg/kg) } & \multicolumn{4}{|c|}{ Recovery (\%) } & \\
\hline & & 1 & 2 & 3 & Average & \\
\hline \multirow{3}{*}{ Soil } & 0.01 & 103.0 & 87.5 & 89.4 & 93.3 & 6.85 \\
\hline & 0.10 & 83.5 & 80.6 & 85.9 & 83.3 & 2.05 \\
\hline & 0.50 & 90.2 & 96.3 & 92.0 & 92.8 & 2.49 \\
\hline \multirow{3}{*}{ Wheat straw } & 0.05 & 88.9 & 84.3 & 85.2 & 86.1 & 2.16 \\
\hline & 0.10 & 102.0 & 89.6 & 86.4 & 92.8 & 6.80 \\
\hline & 0.50 & 92.8 & 85.7 & 84.7 & 87.7 & 3.56 \\
\hline \multirow{3}{*}{ Wheat grain } & 0.01 & 98.9 & 105.0 & 94.3 & 99.5 & 4.50 \\
\hline & 0.10 & 90.2 & 92.9 & 91.7 & 91.6 & 1.25 \\
\hline & 0.50 & 80.8 & 84.4 & 85.7 & 83.6 & 2.05 \\
\hline
\end{tabular}

\begin{tabular}{ccccc} 
& \multicolumn{5}{c}{ TABLE-2 } \\
& HALF-LIVES FOR BENSULFURON METHYL DISSIPATION IN SOIL AND WHEAT STRAW & \\
\hline Matrix & Sample location & Dissipation equation & Correlation coefficient & Half-life (day) \\
\hline \multirow{2}{*}{ Soil } & Beijing & $\mathrm{C}=0.838 \mathrm{e}^{-0.15 \mathrm{t}}$ & 0.963 & 4.62 \\
& Shandong & $\mathrm{C}=0.332 \mathrm{e}^{-0.149 t}$ & 0.960 & 4.65 \\
& Anhui & $\mathrm{C}=0.260 \mathrm{e}^{-0.08 \mathrm{t}}$ & 0.963 & 8.66 \\
\hline \multirow{3}{*}{ Wheat straw } & Beijing & $\mathrm{C}=4.929 \mathrm{e}^{-0.29 \mathrm{t}}$ & 0.964 & 2.39 \\
& Shandong & $\mathrm{C}=2.878 \mathrm{e}^{-0.23 \mathrm{t}}$ & 0.985 & 3.01 \\
& Anhui & $\mathrm{C}=6.278 \mathrm{e}^{-0.171 \mathrm{t}}$ & 0.982 & 4.05 \\
\hline
\end{tabular}



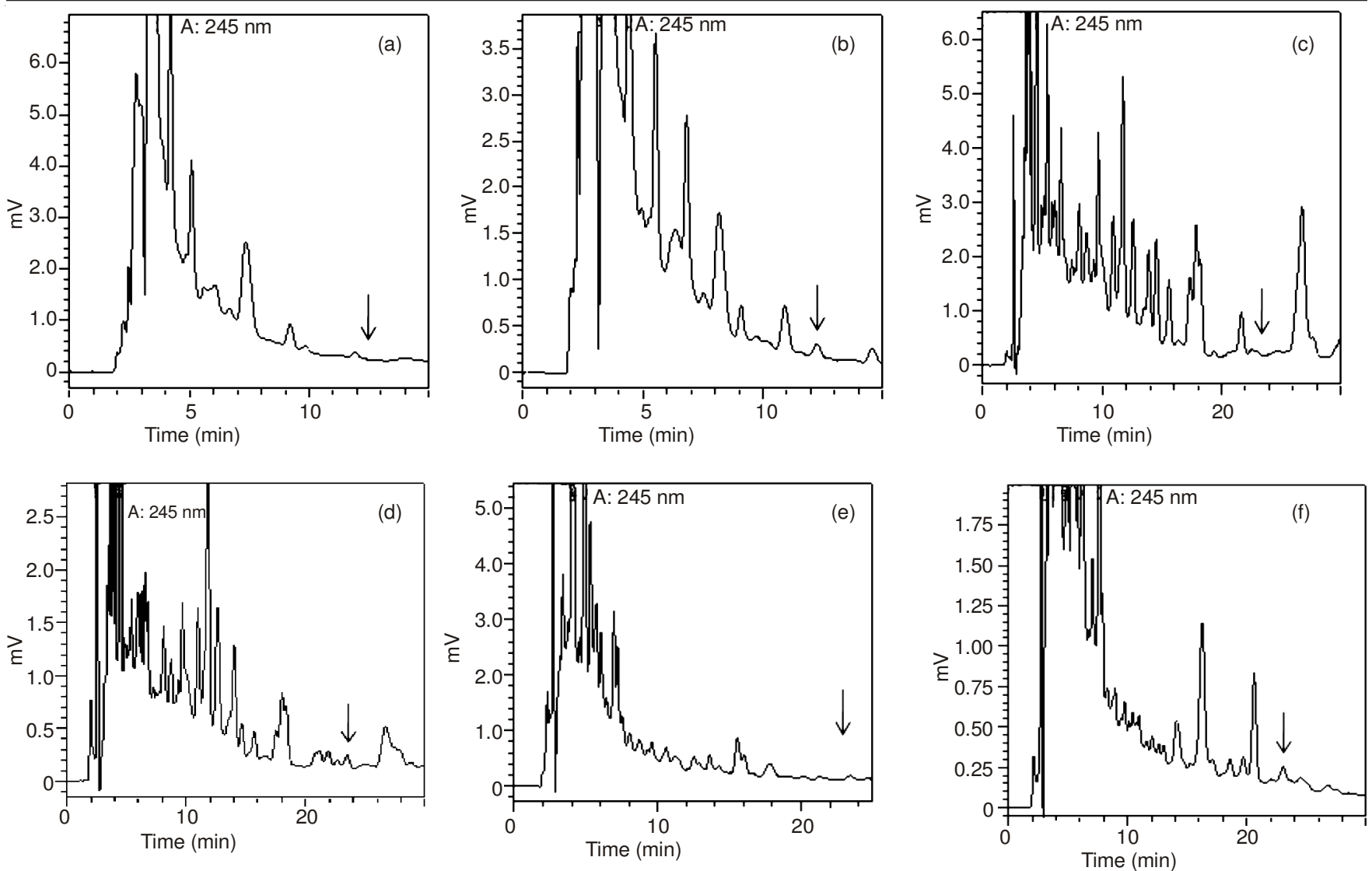

Fig. 2. Typical chromatograms of bensulfuron methyl: (a) blank soil, (b) spiked soil (0.01 mg/kg), (c) blank wheat straw, (d) spiked wheat straw (0.05 mg/ $\mathrm{kg})$, (e) blank wheat grain, (f) spiked wheat grain $(0.01 \mathrm{mg} / \mathrm{kg})$
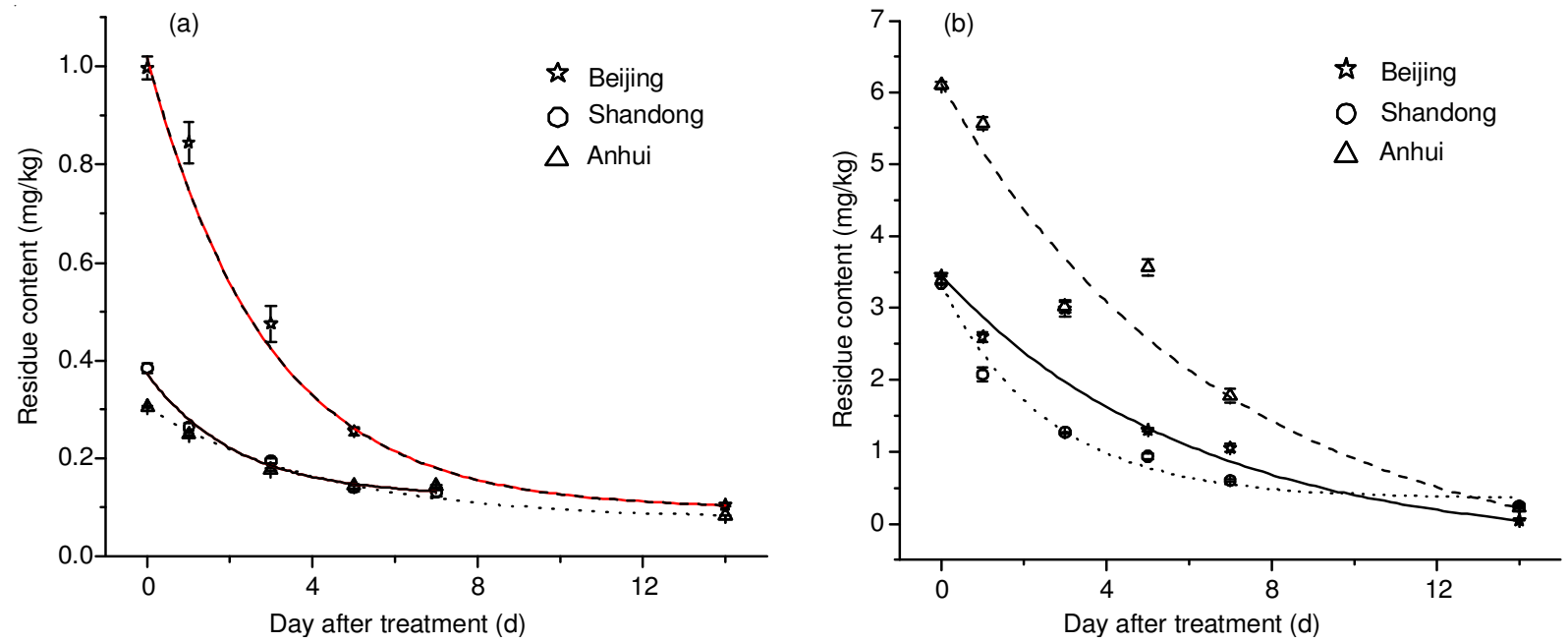

Fig. 3. Dissipation of bensulfuron methyl in soil (a) and wheat straw (b)
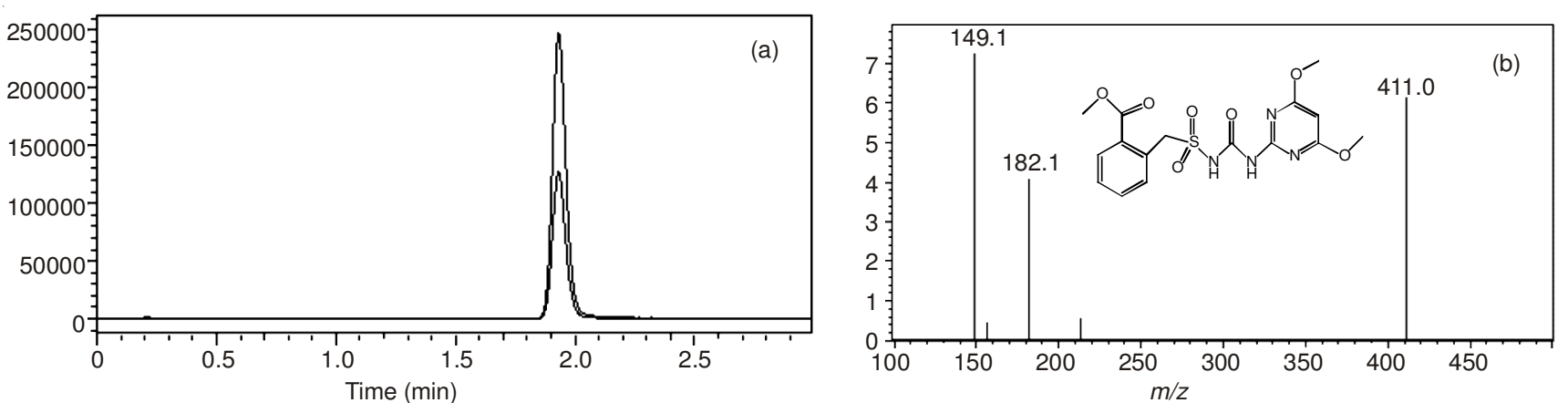

Fig. 4. Total ion chromatogram of field treated soil samples at 0 day (a) and MS spectrum of bensulfuron methyl (b) 


\begin{tabular}{|c|c|c|c|c|c|}
\hline \multirow{3}{*}{ Sample location } & \multicolumn{4}{|c|}{$\begin{array}{c}\text { TABLE-3 } \\
\text { TERMINAL RESIDUES OF BENSULFURON METHYL IN WHEAT FIELD }\end{array}$} & \\
\hline & \multirow{2}{*}{ Dosage (g a.i./ha) } & \multirow{2}{*}{ Interval (days) } & \multicolumn{3}{|c|}{ Residue (mg/kg) } \\
\hline & & & Soil & Wheat straw & Wheat grain \\
\hline \multirow{2}{*}{ Beijing } & 72 & \multirow{2}{*}{51} & $<0.01$ & $0.0985 \pm 0.0019$ & $<0.01$ \\
\hline & 108 & & $<0.01$ & $0.1242 \pm 0.0017$ & $<0.01$ \\
\hline \multirow{2}{*}{ Shandong } & 72 & \multirow{2}{*}{49} & $<0.01$ & - & $<0.01$ \\
\hline & 108 & & $0.0553 \pm 0.0019$ & - & $<0.01$ \\
\hline \multirow{2}{*}{ Anhui } & 72 & \multirow{2}{*}{89} & $<0.01$ & $0.0588 \pm 0.0015$ & $<0.01$ \\
\hline & 108 & & $0.0132 \pm 0.0008$ & $0.0857 \pm 0.0013$ & $<0.01$ \\
\hline
\end{tabular}

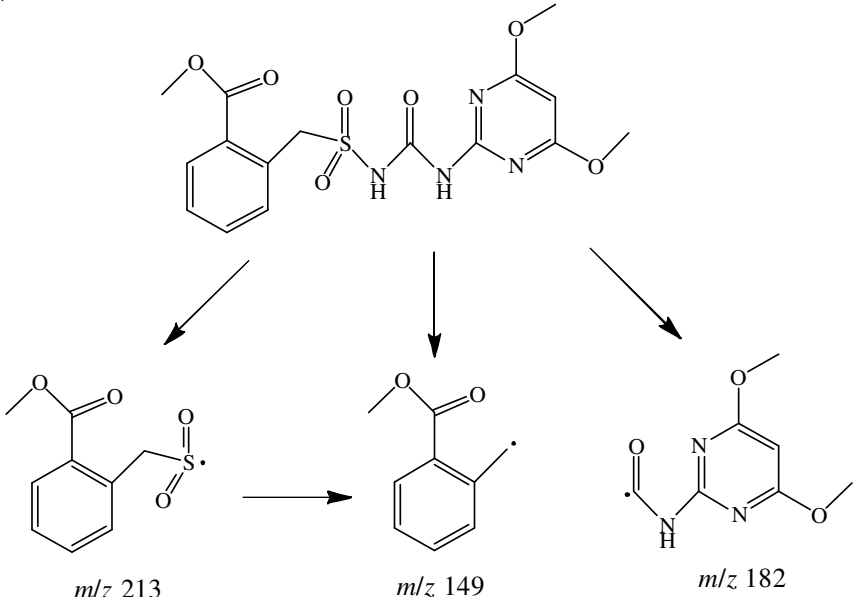

Fig. 5. Probable fragmentation pathways of protonated bensulfuron methyl

factory validation parameters in terms of linearity, lower limits, accuracy and precision. The method has been successfully applied to determine the dissipation and residues of bensulfuron methyl in wheat field. The half-lives of bensulfuron methyl in soil and wheat straw were 4.62-8.66 days and 2.394.05 days, respectively. The terminal residues of bensulfuron methyl in wheat grain were all below MRL value set by China $(0.02 \mathrm{mg} / \mathrm{kg})$. The results indicated that bensulfuron methyl $(60 \%, \mathrm{WDG})$ were safe to apply in wheat field with the suitable dosage and application. This paper will also provide scientific advice for the use of anion exchange column and future residue analysis of sulfonylurea herbicides.

\section{REFERENCES}

1. A.M. El-Ghamry, J.M. Xu, C.Y. Huang and J. Gan, J. Agric. Food Chem., 50, 136 (2002).

2. P. Degelmann, S. Egger, H. Jurling, J. Muller, R. Niessner and D. Knopp, J. Agric. Food Chem., 54, 2003 (2006).

3. Y.T. Lee, C.J. Cui, E.W.L. Chow, N. Pue, T. Lonhienne, J.-G. Wang, J.A. Fraser and L.W. Guddat, J. Med. Chem., 56, 210 (2013).
4. J.K. Lee, K.C. Ahn, O.S. Park, Y.K. Ko and D.W. Kim, J. Agric. Food Chem., 50, 1791 (2002).

5. C. Sabater, A. Cuesta and R. Carrasco, Chemosphere, 46, 953 (2002).

6. R.T. Rosenkrantz, N. Cedergreen, A. Baun and K.O. Kusk, Ecotoxicology, 22, 33 (2013).

7. H. Huang and Z.T. Xiong, Pestic. Biochem. Physiol., 94, 64 (2009).

8. F. Ding, W. Liu, Y. Li, L. Zhang and Y. Sun, J. Lumin., 130, 2013 (2010).

9. X.Y. Lin, Y.Y. Yang, Y.H. Zhao and Q.L. Fu, Ecotoxicology, 21, 1281 (2012).

10. K. Takagi, F.F. Fajardo, M. Ishizaka, T.K. Phong, H. Watanabe and J. Boulange, Paddy Water Environ., 10, 139 (2012).

11. Z.Y. Tan, Z.Y. Guo and Y. Zhang, Chinese J. Hunan Agric. Sci., 8, 20 (2011).

12. L.H. Yang, D.X. Gong, J. Tang, J.K. Luo and C.X. Ding, Chinese J. Chromatogr. A, 30, 71 (2012).

13. Y.J. Wu, X.W. Fu and H. Yang, Arch. Environ. Contam. Toxicol., 61, 359 (2011).

14. C. Chen, L. Yang and J. Zhou, J. Appl. Polym. Sci., 122, 1198 (2011).

15. G.B. Ye, W. Zhang, X. Cui, C.P. Pan and S.R. Jiang, Chinese J. Anal. Chem., 34, 1207 (2006).

16. J. Yang, W.H. Wang, Q. Wang and X.D. Sun, J. Chinese Mass Spectrom. Soc., 32, 176 (2011).

17. S. Kang, N. Chang, Y. Zhao and C.P. Pan, J. Agric. Food Chem., 59, 9776 (2011).

18. J.L. Yuan, G.L. Wang, K. Majima and K. Matsumoto, Anal. Chem., 73, 1869 (2001)

19. J. Zhao, X. Yu, Q. Luo, C. Wei, C. Ke, H. Zuo, X. Yang and J. Yuan, Food Agric. Immunol., 25, 350 (2014).

20. J. Fenoll, P. Hellín, P. Sabater, P. Flores and S. Navarro, Talanta, 101, 273 (2012)

21. Z.L. Chen, R.S. Kookana and R. Naidu, Chromatographia, 52, 142 (2000).

22. Q.Z. Zhu, P. Degelmann, R. Niessner and D. Knopp, Environ. Sci. Technol., 36, 5411 (2002).

23. S. Polati, M. Bottaro, P. Frascarolo, F. Gosetti, V. Gianotti and M.C. Gennaro, Anal. Chim. Acta, 579, 146 (2006).

24. A. Zwir-Ferenc and M. Biziuk, Pol. J. Environ. Stud., 15, 677 (2006).

25. GB 2763-2012, National Food Safety Standard Maximum Residue Limits for Pesticides in Food, Ministry of Health of the People's Republic of China and Ministry of Agriculture of the People's Republic of China.

26. L. Pareja, V. Cesio, H. Heinzen and A.R. Fernández-Alba, Talanta, 83, 1613 (2011). 